\title{
A DFT study on the mechanism of palladium-catalyzed divergent reactions of 1,6-enyne carbonates
}

\author{
XING HUI ZHANG ${ }^{\mathrm{a}, *}$, ZHI YUAN GENG ${ }^{\mathrm{b}}$, TENG NIU $^{\mathrm{a}}$ and KE TAI WANG ${ }^{\mathrm{a}}$ \\ ${ }^{a}$ College of Chemical Engineering, Lanzhou University of Arts and Science, Lanzhou, Gansu 730010, \\ People's Republic of China \\ ${ }^{\mathrm{b}}$ Gansu Key Laboratory of Polymer Materials, College of Chemistry and Chemical Engineering, \\ Northwest Normal University, Lanzhou, Gansu 730070, People's Republic of China \\ e-mail: zhxh135@126.com
}

MS received 5 June 2014; revised 28 August 2014; accepted 18 September 2015

\begin{abstract}
The reaction mechanisms of palladium-catalyzed divergent reactions of 1,6-enyne carbonates have been investigated using DFT calculations at the B3LYP/6-31G(d,p) (LanL2DZ for Pd) level. Solvent effects on these reactions have been considered by the polarizable continuum model (PCM) for the solvent (DMF). The formation of vinylidenepyridines and vinylidenepyrrolidines were generated through 5-exo-dig cyclization or 6-endo-dig cyclization. Our calculation results suggested the following: (i) The first step of the whole cycle is the rate-determining step, which causes allenic palladium intermediate through two plausible pathways. This intermediate provides the corresponding products and releases the palladium catalyst by a subsequent hydrogen transfer and elimination process. (ii) For the catalyst $\mathrm{CH}_{3} \mathrm{OPdH}$, the reaction could occur through two possible pathways, but 5-exo-dig cyclization is favoured over 6-endo-dig cyclization. However, when the hydrogen atom is substituted with a phenyl group, the energy barriers for 5-exo-dig cyclization or 6-endo-dig cyclization become relatively high, $18.0-28.5 \mathrm{kcal} / \mathrm{mol}$. The computational results provide good explanation for the experimental observations.
\end{abstract}

Keywords. 1,6-enyne carbonates; palladium-catalyzed; cyclization; density functional theory.

\section{Introduction}

Propargylic compounds are one of the most important and useful substrates, which can undergo several types of rearrangement promoted via palladium catalysts to give different kinds of allene, alkyne, enyne and alkene derivatives. ${ }^{1,2}$ Propargylic compounds with various nucleophiles by palladium catalysts have been developed as a powerful tool especially for constructing carbon-carbon and carbon-heteroatom bonds over the past few years. ${ }^{3-7}$ Since the first report of Tsuji in 1985 , great progress has been made in developing efficient and selective Pd-catalyzed transformations, as evidenced by the prodigious number of reviews available on various aspects of this growing field. ${ }^{8-21}$ The reactions of allenyl palladium with olefins as nucleophiles are well-known to form carbon-carbon bonds. ${ }^{22-25}$ However, as most of these reactions produce corresponding allenic systems and subsequent rearranged derivatives, much less research interest has been paid to the propargylic substitution reactions of propargylic carbonates with olefins in $\mathrm{Pd}$-catalyzed processes. ${ }^{26-28}$

\footnotetext{
*For correspondence
}

Recently, Liang et al. ${ }^{29}$ studied palladium-catalyzed divergent reactions of enyne carbonates by experiments to synthetise six- or five-membered compounds (scheme 1). According to the experimental results, two proposed mechanisms for the palladium-catalyzed cyclization reactions of enyne carbonates are listed in scheme 2. In scheme 2, first 1,6-enyne carbonates undergoes the $\mathrm{Pd}$-catalyzed transformation to generate allenylpalladium intermediate $\mathbf{A}$ and carbon dioxide. Subsequently, $\mathbf{A}$ is attacked by an olefin nucleophile to form intermediate $\mathbf{B}$ or $\mathbf{D}$, respectively. The intermediates $\mathbf{B}$ and $\mathbf{D}$ provide the corresponding fivemembered heterocyclic allenes $\mathbf{C}$ or six-membered heterocyclic allenes $\mathbf{E}$ by $\beta$-hydrogen elimination, which give the observed products and liberate the palladium catalyst.

To our knowledge, there are no detailed theoretical studies for the palladium-catalyzed divergent reactions reported by Liang group. Here, we present a detailed DFT study on the mechanism of palladium-catalyzed reaction of enyne carbonates to give the corresponding vinylidenepyridines or vinylidenepyrrolidines based on the experiment reported by Liang et al. In the experimental studies, $\operatorname{Pd}(\mathrm{dba})_{2}$ was 


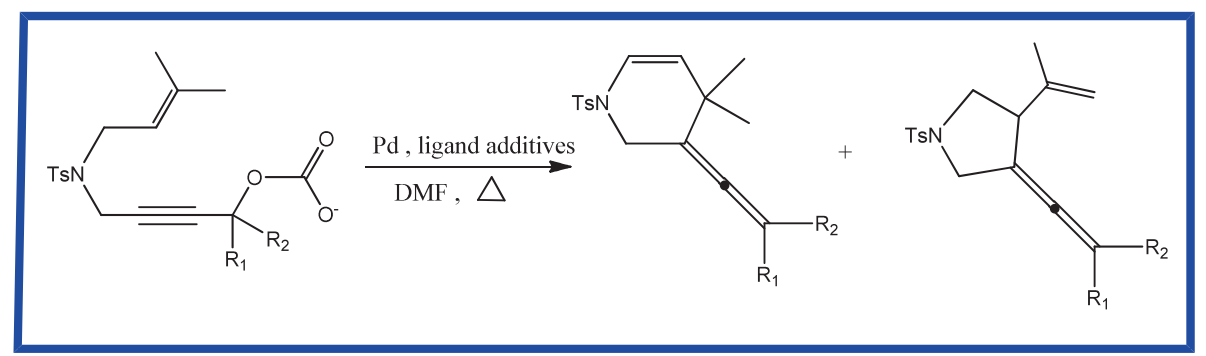

Scheme 1. Palladium-catalyzed synthesis of heterocyclic allenes from 1,6-enyne carbonate.

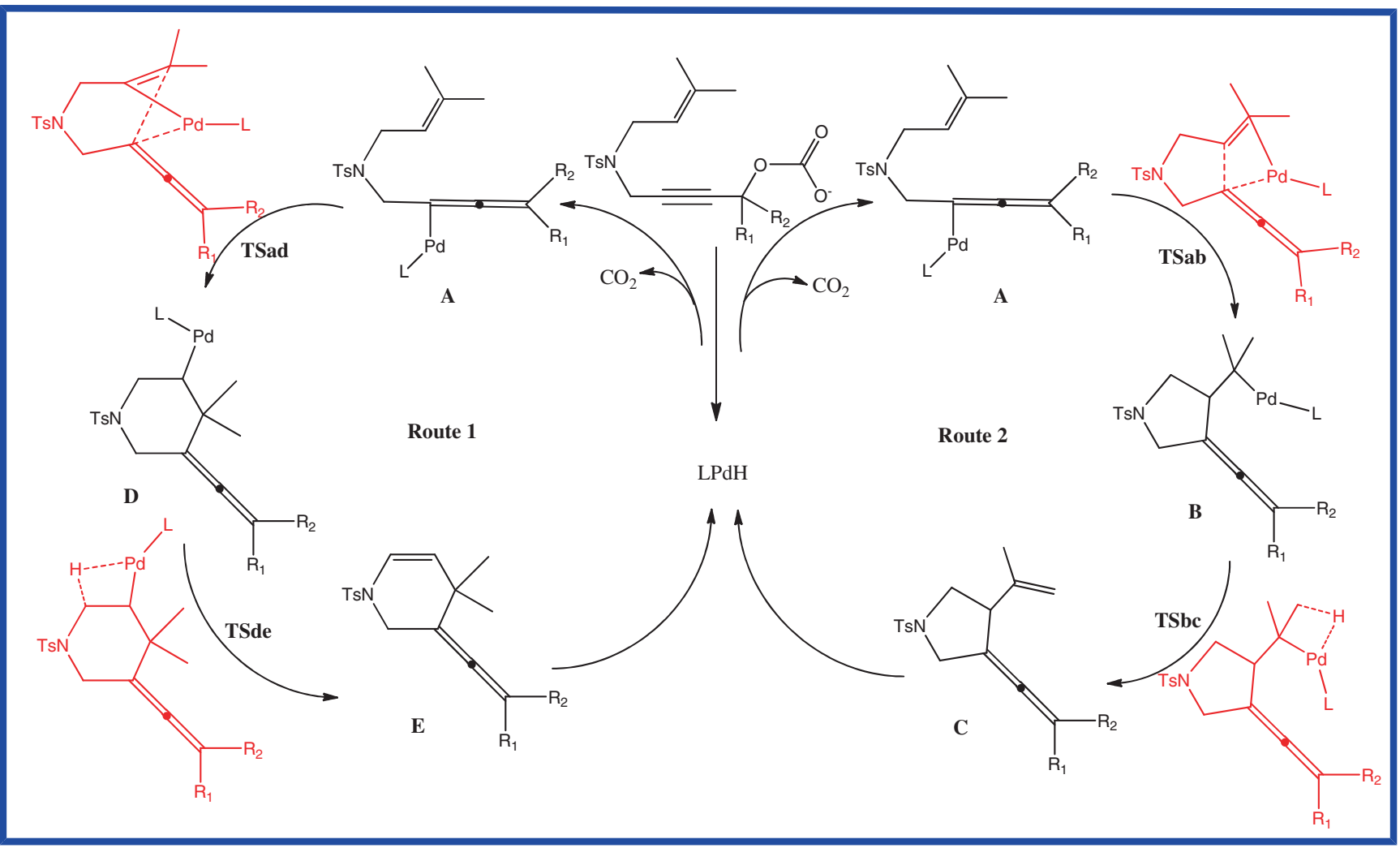

Scheme 2. Two plausible and more detailed mechanisms are envisioned for this novel palladium -catalyzed transformation.

selected as the catalyst. In order to reduce the computational cost, we have simplified this model catalyst to $\mathrm{Pd}(\mathrm{OMe}) \mathrm{H}$.

\section{Computational Methods}

Gaussian 03 program ${ }^{30}$ was used for all the calculations, and all geometries reported were fully optimized at the B3LYP lever of the density functional theory (DFT). ${ }^{31}$ This hybrid DFT method has been successfully applied in the mechanistic studies of transition-metal-catalyzed reaction systems. ${ }^{32,33}$ In calculations, the effective core potentials (ECPs) of Hay and Wadt with the double- $\zeta$ valence basis set (LanL2DZ) were selected to describe $\mathrm{Pd}$ atom, ${ }^{34,35}$ while the $6-31 \mathrm{G}$ basis set with polarization (d) and $(\mathrm{p})^{36}$ were chosen for $\mathrm{H}, \mathrm{C}, \mathrm{N}, \mathrm{O}$ and $\mathrm{S}$ atoms. Natural bond orbital (NBO) analysis was used at the same level. Frequency analyses were calculated in order to ensure that the transition state has only one imaginary frequency, and stable intermediates have no imaginary frequency. The total energies and free energies were calculated at $298.15 \mathrm{~K}$ and $1 \mathrm{~atm}$, and the relative energies are corrected by zero-point energies (ZPE, not scaled). In several significant cases, IRC calculations ${ }^{37}$ were carried out to confirm the connectivity between the transition states and minima (reactants, intermediate and products). To further consider the solvation effects, we calculated single-point salvation energy for all of the species calculated at the B3LYP/PCM/6-311++G(d,p) (LanL2DZ for Pd) level, using UAHF sets of radii on the polarizable continuum model (PCM) ${ }^{38,39}$ Agreeing 
with the experimental conditions $\operatorname{DMF}(\varepsilon=38.3)$ was used as the solvent.

\section{Results and Discussion}

The energy profiles for the possible paths a-d of reaction systems are shown in figures 1 and 2. The optimized structures for the reactants ( $\mathrm{R} 1$ and $\mathrm{R} 2$ ), transition states, intermediates and products of the reaction pathways are shown in figures 3 and 4 . Free energies and the relative energies including zero-point energies of the reaction systems in the gas and solution phases are listed in table 1. Unless otherwise noted, free energies are discussed in DMF solvent.

\subsection{Divergent reaction of 1,6-enyne carbonate $\left(R_{1}=R_{2}=H\right)$ using $\mathrm{CH}_{3} \mathrm{OPdH}$ catalyst}

3.1a 6-Endo-dig cyclization: The energy profile for pathways $\mathrm{a}$ and $\mathrm{b}$ of this reaction process is represented in figure 1. The structures of the various critical points located on the potential surface along with the values of the most relevant geometry parameters are shown in figure 4. As we know, the $\mathrm{C}-\mathrm{C}$ triple bond functional group is characterized via two orthogonal $\pi$ bonds, which has higher energy and easily interact with the $d$ orbitals of transition metals (electrophiles). Meanwhile, the LUMO of alkynes has lower energy, which is easily attacked by strong nucleophiles. Once the alkyne is activated by coordination with the electrophilic metal complex, the alkyne becomes susceptible allenic to be attacked by weaker nucleophiles. Thus, the interaction of the $\mathrm{C}-\mathrm{C}$ triple bond of enyne carbonates with the palladium atom would give the preliminary intermediate R1. From the energy profile it is evident that the first step of pathway indeed involves the preliminary intermediate $\mathbf{R} 1$ stabilized by the coordination of the $\mathrm{Pd}$ atom to the carbon atom of olefin and the $\pi$-bond of the allenic moiety. In R1, this is a polarized complex with distances between $\mathrm{Pd}$ and two $\mathrm{sp}^{2}$-hybridized carbon atoms of 2.146 and $2.111 \AA$, respectively.

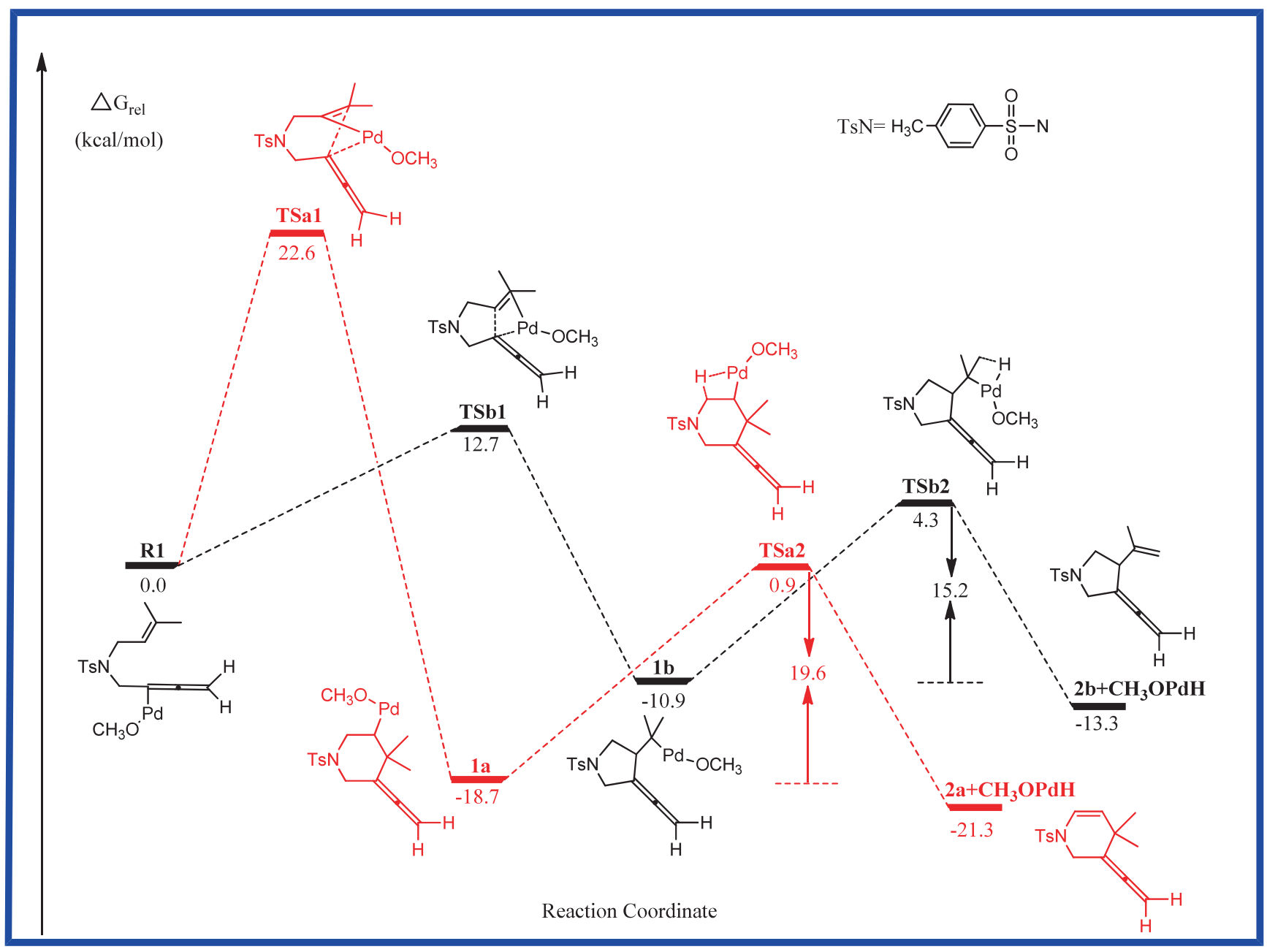

Figure 1. Energy profiles for pathways a (in red) and b (in black). Relative energies are given in $\mathrm{kcal} / \mathrm{mol}$. 


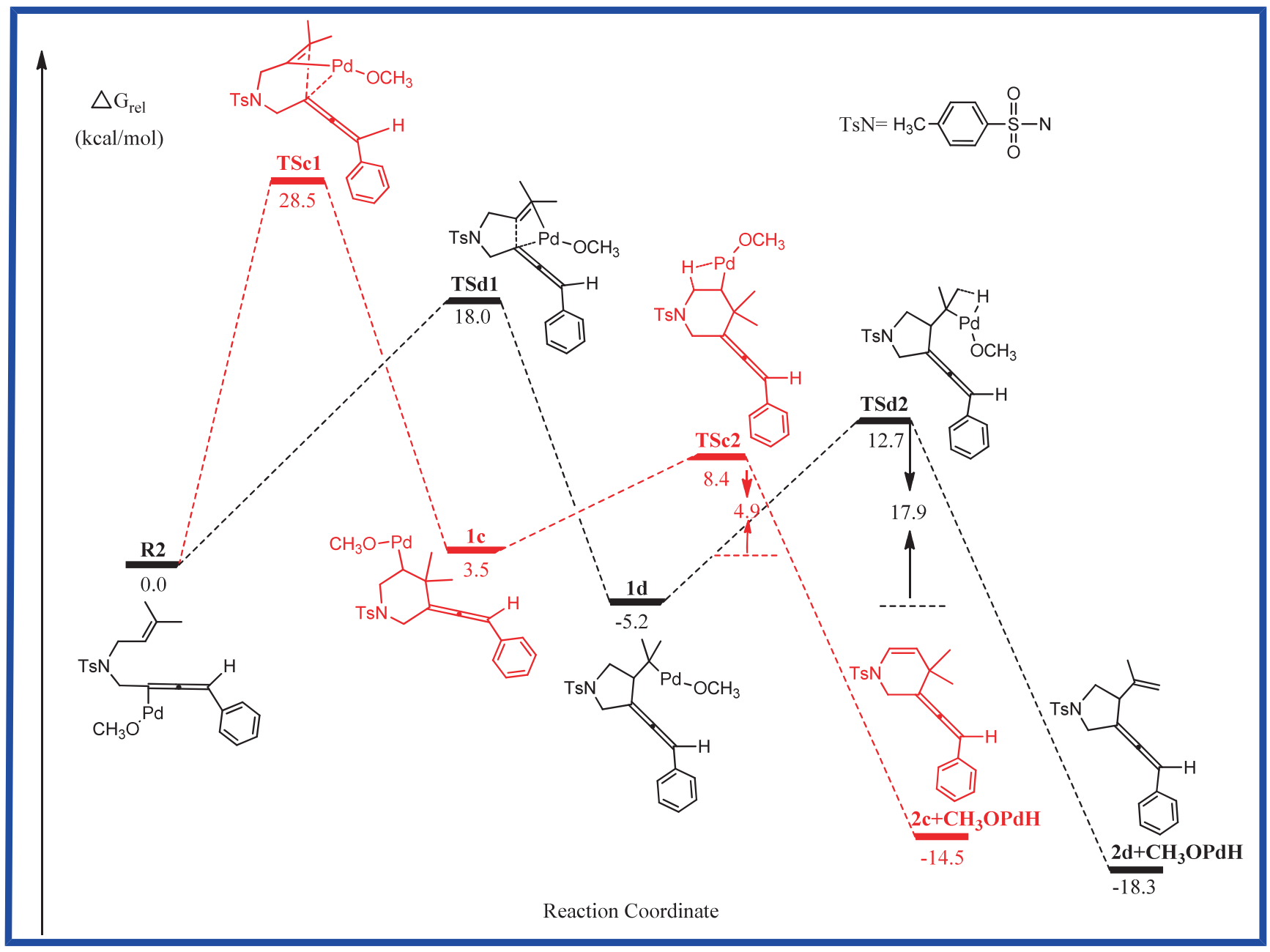

Figure 2. Energy profiles for pathways 'c' (in red) and d (in black). Relative energies are given in kcal/mol.

Furthermore, the $\mathrm{C}^{1}-\mathrm{C}^{2}$ bond has lost a little of its double bond character and is now $1.269 \AA$. Meanwhile, the $\mathrm{Pd}-\mathrm{O}^{1}, \mathrm{~N}-\mathrm{C}^{3}, \mathrm{C}^{3}-\mathrm{C}^{4}$ and $\mathrm{C}^{4}-\mathrm{C}^{5}$ bond lengths are $1.937,1.480,1.506$ and $1.343 \AA$, respectively. Once in $\mathbf{R} 1$, the coordination of the double bond with the palladium atom enhances the electrophilicity and induces a cyclization of the alkenyl carbon $\left(\mathrm{C}^{5}\right)$ onto the double bond $\left(\mathrm{C}^{1}\right)$. A new and stable intermediate structure 1a is formed through a six-membered ring transition structure TSa1 (TSa1 has only one imaginary frequency of $312.7 \mathrm{i} \mathrm{cm}^{-1}$ and IRC calculations confirmed that this TS connects the corresponding reactants and intermediate). Inspection of figure 1 shows that the palladium atom is completely connected with the $\mathrm{C}^{2}$ atom of the allenic group (the bond distance $\mathrm{Pd}-\mathrm{C}^{2}$ is $2.897 \AA$ ) in TSa1 and the bond of the $\mathrm{C}^{1}-$ $\mathrm{C}^{2}$ and $\mathrm{C}^{4}-\mathrm{C}^{5}$ changes from 1.269 to 1.506 and from 1.343 to $1.446 \AA$, respectively. At the same time, palladium atom gradually transferred to the $\mathrm{C}^{4}$ atom, and the bond length of $\mathrm{Pd}-\mathrm{C}^{4}$ is 2.073 in TSa1. Moreover, the transition vector obtained from the frequency computations on TSa1 is dominated by the $\mathrm{C}^{1}-\mathrm{C}^{5}$ bond and the bond distance $\mathrm{C}^{1}-\mathrm{C}^{5}$ is $2.184 \AA$. Table 1 and figure 1 show that the free energy of activation for this step is calculated to be $22.6 \mathrm{kcal} / \mathrm{mol}$ for TSa1 and $-18.7 \mathrm{kcal} / \mathrm{mol}$ for $\mathbf{1 a}$ with respect to $\mathbf{R} \mathbf{1}$. In $\mathbf{1 a}$, it is evident that the $\mathrm{C}^{4}-\mathrm{C}^{5}$ double bond completes its change from a double bond to a single bond $(1.531 \AA$ ) and the $\mathrm{C}^{1}-\mathrm{C}^{5}$ bond becomes completely formed (1.554 $\AA$ ). The $\mathrm{Pd}-\mathrm{C}^{1}$ bond also becomes almost broken and is now $2.253 \AA$. The palladium catalyst has completed the transfer process from $\mathrm{C}^{1}$ to $\mathrm{C}^{4}$ atom. Due to the ring strain of six-membered ring, $\beta$-hydrogen in the intermediate structure $\mathbf{1 a}$ is then eliminated to intermediate 2a by a hydrogen transfer transition structure TSa2. In TSa2; the hydrogen of $\mathrm{C}^{3}$ atom connected in $\mathbf{1 a}$ is transferred to Pd atom, and the lengths of breaking bond $\mathrm{C}^{3}-\mathrm{H}$ is $1.604 \AA$ and the that of forming $\mathrm{Pd}-\mathrm{H}$ bond is $1.573 \AA$. The $\mathrm{Pd}-\mathrm{C}^{4}$ and the $\mathrm{C}^{3}-\mathrm{C}^{4}$ bonds in TSa2 are now 2.105 and $1.430 \AA$, respectively. The $\mathrm{C}^{3}-\mathrm{C}^{4}$ single bond almost completes its change from a single bond to a double bond. The activation of free energy of the 


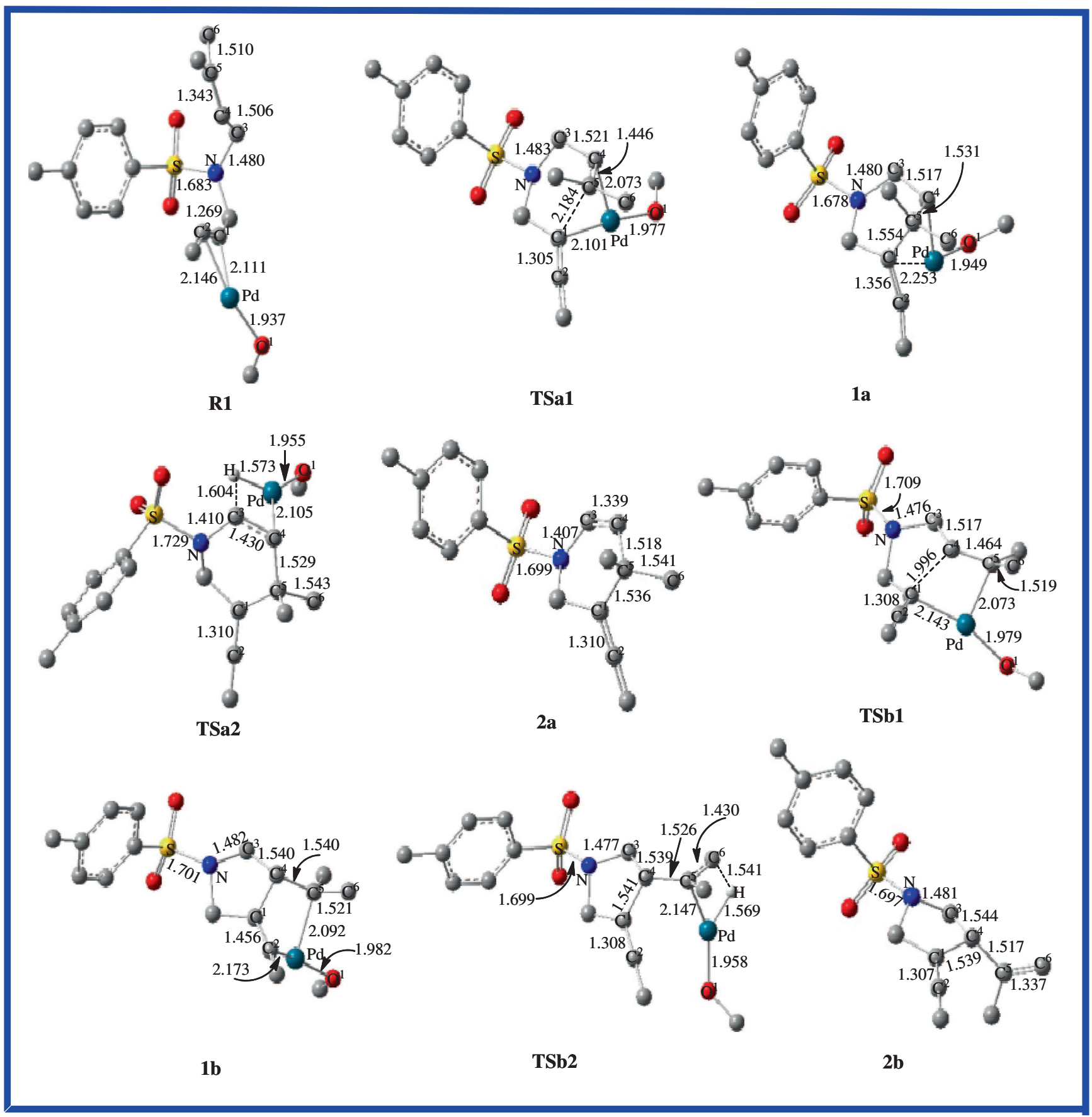

Figure 3. Optimized structures for path ' $a$ ' and ' $b$ ' are shown in figure 1 with selected structural parameters (hydrogen atoms are omitted for clarity and bond lengths are presented in $\AA$ ).

second step was $19.6 \mathrm{kcal} / \mathrm{mol}$, and the formation of 2a is an exergonic process (the free energy of reaction for the $\mathbf{2 a}$ is $-2.6 \mathrm{kcal} / \mathrm{mol}$ with respect to $\mathbf{1 a}$ ). This step for migration of the hydrogen atom results in the formation of the final product (2a) and regeneration of the catalyst $\left(\mathrm{CH}_{3} \mathrm{OPdH}\right)$. The total reaction barrier of pathway ' $\mathrm{a}$ ' is $22.6 \mathrm{kcal} / \mathrm{mol}$, which indicates that the first step is the rate determining one. In total, the whole catalytic process was exothermic by $-21.3 \mathrm{kcal} / \mathrm{mol}$, lower than the reactant $\mathbf{R} \mathbf{1}$. 3.1b 5-Exo-dig cyclization: Apart from 6-endo-dig cyclization, a reaction between the alkenyl carbon $\left(\mathrm{C}^{4}\right)$ and the double bond $\left(\mathrm{C}^{1}\right)$ would give rise to another possible reaction pathway b in $\mathbf{R} \mathbf{1}$. The energy profile for this process is shown in figure 1. The structures of the various critical points located on the potential surface along with the values of the most relevant geometry parameters are presented in figure 4 . Inspection of figure 4 shows that the first step for pathway ' $b$ ' of cyclization would give the new and 


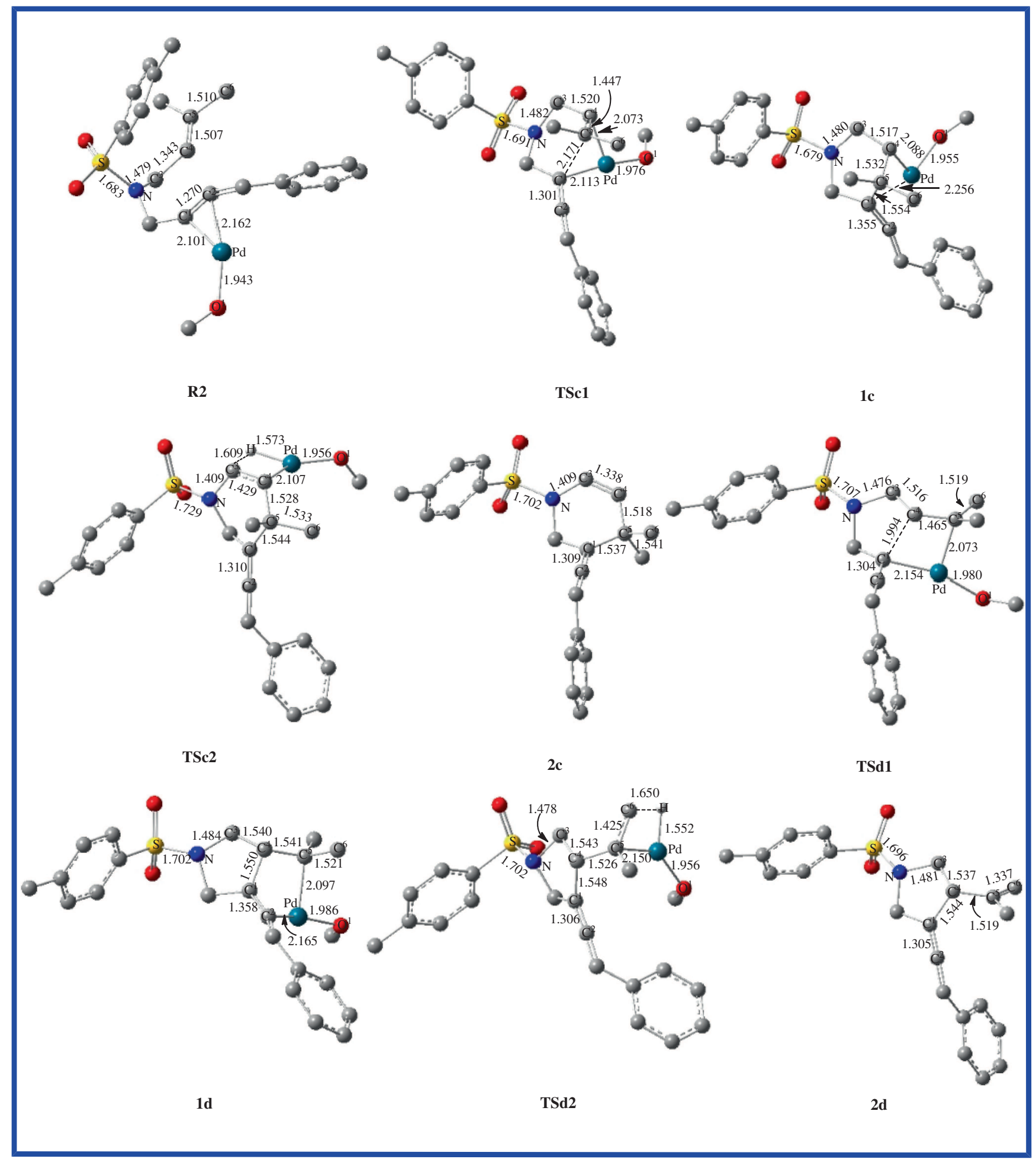

Figure 4. Optimized structures for path $\mathbf{c}$ and $\mathbf{d}$ are shown with selected structural parameters (hydrogen atoms are omitted for clarity and bond lengths are presented in $\AA$ ).

stable structure 1b through the five-membered-ring transition structure TSb1 (TSb1 has only one imaginary frequency of $304.8 \mathrm{i} \mathrm{cm} \mathrm{cm}^{1}$ and IRC calculations confirmed that this TS connects the corresponding reactants and intermediate). The $\mathrm{C}^{1}$ atom is completely connected with the $\mathrm{C}^{4}$ atom of the alkene (the $\mathrm{C}^{1}-\mathrm{C}^{4}$ bond distance is $1.996 \AA$ ) in TSb1 and the $\mathrm{Pd}-\mathrm{C}^{1}$ bond length changes from 2.111 to $2.143 \AA$. In TSb1, the Pd$\mathrm{C}^{5}, \mathrm{Pd}-\mathrm{O}^{1}$ and $\mathrm{C}^{4}-\mathrm{C}^{5}$ distances are 2.073, 1.979 and $1.464 \AA$, respectively. Table 1 and figure 1 show that 
Table 1. Thermodynamic properties (the relative free energy and activation free energy in gas phase and in solution) of the structures in figures 1 and $2 .^{a}$

\begin{tabular}{|c|c|c|c|c|c|c|c|c|}
\hline System & $\Delta E_{\mathrm{gas}}^{\mathrm{rel}}$ & $\Delta E_{\mathrm{gas}}^{\neq}$ & $\Delta G_{\mathrm{gas}}^{\mathrm{rel}}$ & $\Delta G_{\mathrm{gas}}^{\neq}$ & $\Delta E_{\mathrm{sol}}^{\mathrm{rel}}$ & $\Delta E_{\mathrm{sol}}^{\neq}$ & $\Delta G_{\mathrm{sol}}^{\mathrm{rel}}$ & $\Delta G_{\mathrm{sol}}^{\neq}$ \\
\hline R1 & 0.0 & 0.0 & 0.0 & 0.0 & 0.0 & 0.0 & 0.0 & 0.0 \\
\hline TSa1 & 18.9 & 18.9 & 22.5 & 22.5 & 19.4 & 19.4 & 22.6 & 22.6 \\
\hline $1 \mathrm{a}$ & -12.9 & & -8.7 & & -24.5 & & -18.7 & \\
\hline TSa2 & 0.4 & 13.3 & 2.8 & 11.5 & 0.5 & 25.0 & 0.9 & 19.6 \\
\hline $2 \mathrm{a}+\mathrm{CH}_{3} \mathrm{OPdH}$ & -10.2 & & -19.5 & & -9.7 & & -21.3 & \\
\hline TSb1 & 4.5 & 4.5 & 7.8 & 7.8 & 9.6 & 9.6 & 12.7 & 12.7 \\
\hline $1 b$ & -18.0 & & -15.0 & & -15.0 & & -10.9 & \\
\hline $\mathrm{TSb} 2$ & 3.2 & 21.2 & 5.3 & 20.3 & 4.2 & 19.2 & 4.3 & 15.2 \\
\hline $2 \mathrm{~b}+\mathrm{CH}_{3} \mathrm{OPdH}$ & -3.5 & & -13.6 & & -0.4 & & -13.3 & \\
\hline R2 & 0.0 & 0.0 & 0.0 & 0.0 & 0.0 & 0.0 & 0.0 & 0.0 \\
\hline TSc1 & 18.9 & 18.9 & 21.6 & 21.6 & 26.0 & 26.0 & 28.5 & 28.5 \\
\hline $1 \mathrm{c}$ & -11.8 & & -8.8 & & 3.1 & & 3.5 & \\
\hline TSc2 & 1.6 & 13.4 & 3.2 & 12.0 & 8.2 & 5.1 & 8.4 & 4.9 \\
\hline $2 \mathrm{c}+\mathrm{CH}_{3} \mathrm{OPdH}$ & -11.8 & & -22.8 & & -1.0 & & -14.5 & \\
\hline TSd1 & 4.5 & 4.5 & 6.6 & 6.6 & 16.3 & 16.3 & 18.0 & 18.0 \\
\hline $1 \mathrm{~d}$ & -17.2 & & -15.7 & & -7.7 & & -5.2 & \\
\hline TSd2 & 3.1 & 20.3 & 4.9 & 20.6 & 12.6 & 20.3 & 12.7 & 17.9 \\
\hline $2 \mathrm{~d}+\mathrm{CH}_{3} \mathrm{OPdH}$ & -4.2 & & -15.9 & & -4.1 & & -18.3 & \\
\hline
\end{tabular}

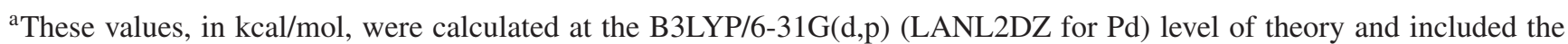
zero-point energy correction, using single-point PCM calculations at the B3LYP/PCM/6-311++G(d,p)//B3LYP/6-31G(d,p) (LanL2DZ for Pd) level of theory to model the effect of the solvent (DMF)

the free energy of activation for this step is calculated to be $12.7 \mathrm{kcal} / \mathrm{mol}$ for TSb1 and the free energy of reaction for the $\mathbf{1 b}$ intermediates is $-10.9 \mathrm{kcal} / \mathrm{mol}$ with respect to R1. The lower barriers found for TSb1 in comparison to those of TSa1 can be mainly attributed to the following reasons. The NBO charges for the $\mathrm{C}^{1}$, $\mathrm{C}^{4}$ and $\mathrm{C}^{5}$ atoms of $\mathbf{R} \mathbf{1}$ are $0.099,-0.117$ and $0.972 \mathrm{au}$, respectively. A positive charge found for the $\mathrm{C}^{1}$ atom makes the nucleophilic attack of $\mathrm{C}^{4}$ on the positively charged $\mathrm{C}^{1}$ more feasible than that of the $\mathrm{C}^{5}$ atom. Just as is exhibited by the structure of $\mathbf{1 a}$, the $\mathrm{C}^{1}-\mathrm{C}^{4}$ and the $\mathrm{Pd}-\mathrm{C}^{5}$ bonds in $\mathbf{1 b}$ also become completely formed and are now 1.549 and $2.092 \AA$, respectively. Furthermore, the $\mathrm{C}^{4}-\mathrm{C}^{5}$ bond also accomplished the conversion of the double bond to a single bond, and now the bond distance is $1.540 \AA$. The subsequent step for migration of the hydrogen atom results in the formation of the final product ( $\mathbf{2} \mathbf{b})$ and regeneration of the catalyst $\left(\mathrm{CH}_{3} \mathrm{OPdH}\right)$ through $\mathbf{T S b 2}$. Figure 2 shows that the $\mathrm{C}^{6}-\mathrm{H}$ and $\mathrm{Pd}-\mathrm{H}$ distances are 1.541 and 1.569 $\AA$ in TSb2, respectively. Meanwhile, the $C^{5}-C^{6}$ and Pd- $\mathrm{C}^{5}$ bond lengths changed from 1.521 to $1.430 \AA$ and from 2.092 to $2.147 \AA$, respectively. The activation free energy of the step is $15.2 \mathrm{kcal} / \mathrm{mol}$, and the formation of product $\mathbf{2} \mathbf{b}$ is an exothermic process (the free energy of reaction for the $\mathbf{2 b}$ is $-2.4 \mathrm{kcal} / \mathrm{mol}$ with respect to 1b), and the whole catalytic process is exothermic by $-13.3 \mathrm{kcal} / \mathrm{mol}$. Comparison of the structure of TSa2, the activation free energy of this step for TSb2 is lower than that for $\mathbf{T S a} 2$ by $4.4 \mathrm{kcal} / \mathrm{mol}$. It is therefore obvious that the first step of the two pathways is rate determining for the whole catalytic process. The relatively high barriers found for both of the two different pathways. The higher barriers found for TSa1 indicate that the reaction pathway for 5-exo-dig cyclization is more feasible than that of 6-endo-dig cyclization. Our calculated results are also consistent with the experimental observations of Liang et al. for the palladium-catalyzed divergent reactions of 1,6-enyne carbonate.

\subsection{Divergent reaction of 1,6-enyne carbonate $\left(R_{1}=H, R_{2}=P h\right)$ using $\mathrm{CH}_{3} \mathrm{OPdH}$ catalyst}

To further improve our understanding of the palladiumpromoted reactions for different unsaturated substrates as proposed in scheme 1, we have done additional calculations to begin to study the reactivity via a ligand exchange of hydrogen atom (the group is marked as $\mathrm{R}_{2}$ in scheme 1 and 2) in $\mathbf{R} \mathbf{1}$ with phenyl group. Following the originally proposed mechanism and the model studies, the detailed mechanism of formation is displayed in figure 3 and similar reaction pathways have been determined for the reaction systems. The structures of the various critical points located on the potential surface along with the values of the most relevant geometry parameters are presented in figure 3. 
3.2a 6-Endo-dig cyclization: Examination of figure 2 shows that the first step for pathway 'c' also involves the preliminary intermediate $\mathbf{R} \mathbf{2}$, stabilized by the coordination of the Pd atom to the $\pi$ bond of the allene moiety. In R2, the $\mathrm{Pd}-\mathrm{C}^{1}$ distance is $2.101 \AA$ and the lengths of the $C^{1}-C^{2}$ bond is $1.270 \AA$. Structure $\mathbf{R 2}$ causes a cyclization of the $\mathrm{C}^{1}$ atom of allene onto the double bond $\left(\mathrm{C}^{5}\right)$ and gives the new and stable structure 1c through the six-membered-ring transition structureTSc1 In TSc1, the new $\mathrm{C}^{1}-\mathrm{C}^{5}$ bond is 2.171 $\AA$. Figure 2 and table 1 shows that the activation free energy for this step is calculated to be $28.5 \mathrm{kcal} / \mathrm{mol}$ for TSc1 and the free energy of the reaction for the intermediate $1 \mathrm{c}$ is $-3.5 \mathrm{kcal} / \mathrm{mol}$ with respect to $\mathbf{R 2}$. The higher activation free energy found for this step indicates that it is also the rate-determining step. The higher barrier found for TSc1 in comparison to that for TSa1 indicated that an iodine group would greatly reduce the positive charge of $\mathrm{C}^{5}$ ( 0.855 and 0.714 au for $\mathbf{R} 1$ and $\mathbf{R} 2$ respectively). The next step for a hydrogen transfer and elimination reaction process produces the formation of the final product $(\mathbf{2 c})$ and regeneration of the catalyst $\left(\mathbf{C H}_{3} \mathbf{O P d H}\right)$ through $\mathbf{T S c} 2$. The activation free energy of the step is $4.9 \mathrm{kcal} / \mathrm{mol}$, and the formation of $\mathbf{2 a}$ is an exothermic process (the free energy of reaction for $\mathbf{2 c}$ is $18.0 \mathrm{kcal} / \mathrm{mol}$ with respect to $1 \mathrm{c})$. These total catalytic cycle steps are exothermic by $-14.5 \mathrm{kcal} / \mathrm{mol}$.

3.2b 5-Exo-dig cyclization: As we mentioned above, attack between the $\mathrm{C}^{1}$ and the $\mathrm{C}^{4}$ atom of the double bond would also give rise to another possible reaction pathway 'd' through $\mathbf{R 2}$ Examination of figure 2 shows that the first step for pathway ' $d$ ' also involves the preliminary intermediate R2. Cyclization of the $\mathrm{C}^{1}$ atom onto the double bond $\left(\mathrm{C}^{4}\right)$ would give the new and stable structure 1d through the fivemembered-ring transition structure TSd1. According to our calculated results, figure 4 shows that the $C^{1}-C^{4}$ bond distance is 1.994 $\AA$ in TSd1. In TSd1, palladium complex has migrated from the $\mathrm{C}^{2}$ to the $\mathrm{C}^{5}$ atom, and the Pd-C $\mathrm{C}^{5}$ distance in TSd1 is $2.073 \AA$. Table 1 shows that the activation free energy for this step is calculated to be $18.0 \mathrm{kcal} / \mathrm{mol}$ for TSd1 and the free energy of the reaction for the intermediate $\mathbf{1 d}$ is $-5.2 \mathrm{kcal} / \mathrm{mol}$ with respect to $\mathbf{R} 2$. The relatively lower barriers are found for TSd1 in comparison to those for TSc1 $(28.5 \mathrm{kcal} / \mathrm{mol})$. It is important to point out that this step is also the rate-determining step for the pathway. However the reaction pathway via TSb1 only needs to overcome a barrier of $12.7 \mathrm{kal} / \mathrm{mol}$, some $5.3 \mathrm{kcal} / \mathrm{mol}$ lower than that for TSd1. The $\mathrm{C}^{1} \mathrm{C}^{4}$ and Pd- $\mathrm{C}^{5}$ bonds are 1.550 and $2.097 \AA$ in $\mathbf{1 d}$, respectively. The subsequent step for migration of the hydrogen atom to palladium atom results in the product $(\mathbf{2 d})$ and regeneration of the catalyst $\left(\mathbf{C H}_{\mathbf{3}} \mathbf{O P d H}\right)$ via $\mathbf{T S d} 2$. Furthermore, the $\mathrm{C}^{5}-\mathrm{C}^{6}$ bond also accomplished the conversion of the single bond to a double bond and now the bond distance is $1.337 \AA$ in TSd2. The final barrier of $17.9 \mathrm{kcal} / \mathrm{mol}$ is required to release the product and regenerate the catalyst. This final step is exothermic by $-13.1 \mathrm{kcal} / \mathrm{mol}$. The lower barrier found for TSd1 in comparison to that for TSc1 indicates that 5exo-dig cyclization of the nucleophile onto the internal carbon of the alkyne with a phenyl group is favoured.

As shown in table 1, for the consideration of the solvent effect of the reaction systems the activation free energies of the first steps (Tsa1, TSb1, TSc1 and TSd1) are increased than that of the gas phase. However, the activation free energies of the subsequent steps (Tsa2, TSb2, TSc2 and TSd2) in solution are decreased compared to those of the gas phase, indicating that the $\mathrm{CC}$ bond cyclization process of the solvent DMF is disadvantageous, and the solvent DMF is more favourable for the hydrogen transfer process.

\subsection{5-Exo-dig Cyclization vs 6-Endo-dig Cyclization}

According to the experimental results, palladiumcatalyzed divergent cyclizations of 1,6-enyne carbonates can be combined with Suzuki coupling to prepare highly functionalized 3-vinylidene-1-tosylpyrrolidines. Two general mechanisms have been postulated to explain the formation of 5-exodig cyclization and 6endo-dig cyclization (scheme 1). Our calculated results clearly suggest that the hydrogen migration process has lower activation energies for the catalytic reaction systems, and the first step of 5-exodig cyclization and 6 -endo-dig cyclization is the rate-limiting step for 1,6enyne carbonates. The results show that in the reaction of 1,6-enyne carbonate $\left(\mathrm{R}_{1}=\mathrm{R}_{2}=\mathrm{H}\right)$ with $\mathrm{CH}_{3} \mathrm{OPdH}$ both 5-exodig cyclization and 6-endo-dig cyclization (pathways ' $a$ ' and 'b') are feasible, with a barrier height of 22.6 and $12.7 \mathrm{kcal} / \mathrm{mol}$, respectively. While the reaction for the pathway ' $b$ ' takes place more easily. They can also promote divergent reactions of 1,6-enyne carbonate at experimental temperatures due to their relatively low activation energies. For 1,6-enyne carbonate $\left(\mathrm{R}_{1}=\mathrm{H} \mathrm{R}_{2}=\mathrm{Ph}\right)$, it is widely favoured that the 5 -exodig cyclization over 6-endo-dig cyclization represents the reaction reality, the reaction barriers of the pathway 'c' $(28.5 \mathrm{kcal} / \mathrm{mol})$ are much higher than those of the pathway $\mathrm{d}(18.0 \mathrm{kcal} / \mathrm{mol})$. However, the reaction for $\mathbf{R} 2$ (phenyl group substitution of the hydrogen atom of R1) have relatively higher activation barriers of 18.0 $28.5 \mathrm{kcal} / \mathrm{mol}$ and the reactions produce products of 5exodig cyclization at relatively high temperatures. The 
above comparison is qualitatively consistent with the experimental reaction and helps to provide a reasonable explanation for understanding some basic factors that determine the reactivity of these types of unsaturated substrates and their reaction pathways for the divergent reaction promoted by palladium catalyst.

\section{Conclusions}

In summary, this work has provided the first theoretical study for the reaction of the palladium-catalyzed divergent reactions of 1,6-enyne carbonates. According to our calculations, the reaction proceeds through two possible channels. The first step of the catalytic cycle is the addition of the vinyl carbon atom onto the triple bond to form an allenic palladium intermediate through 5-exo-dig cyclization or 6-endo-dig cyclization. Subsequently, allenic palladium intermediate undergoes hydrogen transfer and elimination reactions to produce the observed products and liberate the palladium catalyst. For the two different reaction pathways, the first step is the rate-determining step. For the catalyst $\mathrm{CH}_{3} \mathrm{OPdH}$, this reaction could occur through two possible pathways where 5-exo-dig cyclization is easier than 6-endo-dig cyclization. On the other hand, when the hydrogen atom is substituted with a phenyl group, the energy barriers for 5-exo-dig cyclization or 6-endo-dig cyclization are relatively higher, 18.0-28.5 $\mathrm{kcal} / \mathrm{mol}$ and the reactions occur at relatively higher temperatures. Our computational results provide explanation for the experimental observations of Liang group for the palladium-catalyzed divergent reaction of 1,6enyne carbonates.

\section{Supporting Information}

The Cartesian coordinates for the calculated stationary structures and the sum of the electronic and zero-point energies for the transition and ground states obtained from the DFT calculations are available at www.ias.ac. in/chemsci.

\section{Acknowledgement}

This work was supported by Longyuan young creative talents to support projects, Gansu Province (201498), and New Chemical Materials Research and Innovation team project. We are grateful to the Gansu Province Supercomputer Center for essential support. We are grateful to the reviewers for their invaluable suggestions.

\section{References}

1. Tsuji J and Mandai T 1995 Angew. Chem. Int. Ed. Engl. 342589

2. Tsuji J 2004 In Palladium reagents and catalysts (England: John Wiley) p. 543

3. Dixneuf P H, Guyot T, Ness M D and Roberts S M 1997 Chem. Commun. 212083

4. Tsuji Y, Taniguchi M, Yasuda T, Kawamura T and Obora Y 2000 Org. Lett. 22635

5. Matsuda I, Komori K I and Itoh K $2002 \mathrm{~J}$. Am. Chem. Soc. 1249072

6. Kondo T, Kanda Y, Baba A, Fukuda K, Nakamura A, Wada K, Morisaki Y and Mitsudo T A $2002 \mathrm{~J}$. Am. Chem. Soc. 12412960

7. Inada Y, Nishibayashi Y, Hidai M and Uemura S 2002 J. Am. Chem. Soc. 12415172

8. Tsuji J, Watanabe H, Minami I and Shimizu I $1985 \mathrm{~J}$. Am. Chem. Soc. 1072196

9. Tsuji J, Sugiura T and Minami I 1986 Tetrahedron Lett. 27731

10. Tsuji J and Mandai T 1993 J. Organomet. Chem. 45115

11. Arzoumanian H, Choukrad M and Nuel D $1993 \mathrm{~J}$. Mol. Catal. 85287

12. Marshall J A, Wolf M A and Wallace E M 1997 J. Org. Chem. 62367

13. Bi H P, Liu X Y, Gou F R, Guo L N, Duan X H, Shu X Z and Liang Y M 2007 Angew. Chem., Int. Ed. 467068

14. Guo L N, Duan X H,Bi H P, Liu X Y and Liang Y M 2007 J. Org. Chem. 721538

15. Bi H P, Liu X Y, Gou F R, Guo L N, Duan X H and Liang Y M 2007 Org. Lett. 93527

16. Bi H P, Guo L N, Gou F R, Duan X H, Liu X Y and Liang Y M 2008 J. Org. Chem. 734713

17. Shu X Z, Ji K G, Zhao S C, Zheng Z J, Chen J, Lu L, Liu X Y and Liang Y M 2008 Chem. Eur. J. 1410556

18. Gou F R, Huo P F, Bi H P, Guan Z H and Liang Y M 2009 Org. Lett. 113418

19. Zhao S C, Shu X Z, Ji K G, Zhou A X, He T, Liu X Y and Liang Y M 2011 J. Org. Chem. 761941

20. Chen Z S, Duan X H, Wu L Y, Shaukat A, Ji K G, Zhou P X, Liu X Y and Liang Y M 2011 Chem. Eur. J. 174986

21. Guo L N, Duan X H and Liang Y M 2011 Acc. Chem. Res. 44111

22. Grigg R, Rasul R, Redpath J and Wilson D 1996 Tetrahedron Lett. 374609

23. Akpınar G E, Kus M, Ucüncü M, Karakus E and Artok L 2011 Org. Lett. 13748

24. Bohmer J and Grigg R 1999 Tetrahedron 5513463

25. Luo Y and Wu J 2012 Org. Lett. 141592

26. Tsutsumi K, Yabukami T, Fujimoto K, Kawase T, Morimoto T and Kakiuchi K 2003 Organometallics 22 2996

27. Yoshida M, Higuchi M and Shishido K 2008 Tetrahedron Lett. 491678

28. Yoshida M, Higuchi M and Shishido K 2010 Tetrahedron 662675

29. Zhao S C, Ji K G, Lu L, He T, Zhou A X, Yan R L, Ali S, Liu X Y and Liang Y M 2012 J. Org. Chem. 772763

30. Frisch M J, Trucks G W, Schlegel H B, Scuseria G E, Robb M A,Cheeseman J R, Zakrzewfki V G, 
Montgomery J A, Stratmann R E, Burant J C, Dapprich S, Millam J M, Daniels AD, Kudin K N, Strain M C, Farkas O, Tomasi J, Barone V, Cossi M, Cammi R, Mennucci B, Pomelli C, Adamo C, Clifford F, Ochterski J, Petersson G A, Ayala P Y, Cui Q, Morokuma K, Malick D K, Rabuck A D, Raghavachari K, Foresman J B, Cioslowski J, Ortiz J V, Stefanov B B, Liu G, Liashenko A, Piskorz P, Komaromi I, Gomperts R, Martin R L, Fox D J, Keith T, Al-Laham M A, Peng C Y, Nanayakkara A, Gonzalez C, Challacombe M, Gill P M W, Johnson B G, Chen W, Wong M W, Andres J L, Head-Gordon M, Replogle E S, Pople J A 2004 GAUSSIAN 03 (Revision E01), Gaussian, Inc., Pittsburgh PA
31. Stephens P J, Devlin F J and Chabalowski C F 1994 J. Phys. Chem. 9811623

32. Soriano E and Marco-Contelles J 2009 Acc. Chem. Res. 421026

33. Dub P A and Poli R 2010 J. Am. Chem. Soc. 13213799

34. Hay P J and Wadt W R 1985 J. Chem. Phys. 82270

35. Wadt W R and Hay P J 1985 J. Chem. Phys. 82284

36. Rassolov V A, Ratner M A, Pople J A, Redfern P C and Curtiss L A 2001 J. Comput. Chem. 22976

37. Gonzalez C and Schlegel H B 1989 J. Chem. Phys. 90 2154

38. Tomasi J and Persico M 1994 Chem. Rev. 942027

39. Mineva T, Russo N and Sicilia E 1998 J. Comput. Chem. 19290 